\title{
Curriculum Vitae of Zoltán Ésik
}

\section{Education and Academic Degrees}

1. Doctor of the Hungarian Academy of Science (DSc), 1996. Thesis: Iteration Theories.

2. Habilitation in Computer Science: Attila József University, Szeged, 1995. Thesis: Iteration Theories.

3. Candidate of Mathematical Sciences: Hungarian Academy of Sciences, 1985. Thesis: Top-down tree transformations.

4. University Doctor (PhD): Attila József University, Szeged, 1979. Thesis: Decidability results concerning tree transformations.

5. University Diploma (MSc) in Mathematics: Attila József University, Szeged, 1974.

\section{Employment and related activities}

1. 2003-2016 : Head of the Department of Foundations of Computer Science.

2. 1997-2016 : Full Professor, Department of Foundations of Computer Science, Institute of Informatics, University of Szeged (formerly: Attila József University), Hungary.

3. 1996-1997: Part-time Associate Professor, Institute of Mathematics and Informatics, Lajos Kossuth University, Debrecen.

4. 1990-1996: Associate Professor, Department of Foundations of Computer Science, Institute of Informatics, Attila József University, Szeged, Hungary.

5. 1987-1989: Associate Professor, Department of Computer Science, Institute of Mathematics, Attila József University, Szeged, Hungary.

6. 1979-1986: Assistant Professor, Department of Computer Science, Institute of Mathematics, Attila József University, Szeged, Hungary.

7. 1974-1978: Assistant Lecturer, Department of Computer Science, Institute of Mathematics, Attila József University, Szeged, Hungary. 


\section{Visiting Positions and Fellowships}

1. Visiting Scientist, Kyoto Sangyo University, Kyoto, Japan: September 2008, September 2007, October 2006, June 2005, August 2003, September 2002, January 2001 and March 2000.

2. Visiting Professor, University of Bordeaux, France: May 2003.

3. Visiting Professor, TU Dresden, Germany: June-July 2002.

4. Visiting Professor, LIAFA, Denis Diderot University, Paris: May 2002.

5. Visiting Professor, University of Aalborg, Denmark: May 2001-April 2002.

6. Visiting Professor, University of Waterloo, Canada: June 2000.

7. Visiting Professor, University of Aizu, Japan: January-June 1999.

8. Fulbright Research Fellow, Stevens Institute of Technology, Hoboken, USA: June-September 1997.

9. JSPS Research Fellow, Kyoto Sangyo University, Japan: February - April, 1997.

10. Visiting Professor, LIAFA, Université Paris 6 and 7, France: May 1997.

11. Alexander von Humboldt Research Fellow, Institute of Informatics, University of Stuttgart, Germany: September-November 1994.

12. COST Research Fellow, LFCS, Department of Computer Science, The University of Edinburgh, UK: September-November 1993.

13. Visiting Professor, Department of Computer Science, Stevens Institute of Technology, New Jersey, USA: September-November 1990.

14. Alexander von Humboldt Research Fellow, Institute of Informatics, TU Munich, Germany: 1988-1989.

15. Visiting Professor, Department of Pure and Applied Mathematics, Stevens Institute of Technology, New Jersey, USA: September 1983-August 1984.

\section{Courses Conducted}

Mathematical foundations of logic and functional programming. Process algebra. Finite transition systems. Finite model theory. Logic in computer science. Foundations of computer science. Category theory in computer science. Universal algebra in computer science. Complexity theory. Computability theory. Iteration theories. Automata and formal languages. Introduction to analysis. Linear algebra. Automata and formal logic. Compilers. Mathematical logic. Algebraic and 
graph theoretic properties of block schemes. Formal semantics. Algorithm theory. Mathematical foundations of software. Mathematical foundations of programming. System programming.

\section{Research Interest}

Automata and formal language theory. Algebra, categories and logic in computer science. Fixed point theory. Iteration theories. Temporal logics. Concurrency. Semantics.

\section{Publications}

Two books, four book chapters, 32 edited volumes, approx. 250 research articles.

\section{Editorial Work}

Member of the Editorial Board of: Journal of Automata, Languages and Combinatorics (2016), Journal of Mathematics and Computer Science (2009-2016), Alkalmazott Matematikai Lapok (Journal of Applied Mathematics, in Hungarian, 2004-2016), Theoretical Computer Science (1999-2015), Theoretical Informatics and Applications (1998-2016), Discrete Mathematics and Theoretical Computer Science (1996-2001), Acta Cybernetica (1987-2016), Acta Scientiarium Mathematica (1986-2000), Algebra (Hindawi Publishers).

Membership in International Learned Bodies and Professional Associations

1. Fellow of the EATCS, 2016.

2. Member of the Presburger Award Committee, 2015-2016.

3. Member of the Academia Europaea, 2010-2016.

4. Member of the Steering Committee of the FICS workshop series, 2009-2012.

5. Member of the Steering Committee of the Algebraic Informatics conference series, 2007-2016.

6. Member of the Board of the European Association for Computer Science Logic, 2005-2016.

7. Member of the WG 1.8 (Concurrency) of IFIP TC1.

8. Member of the Council of the European Association for Theoretical Computer Science (EATCS), 2004-2016. 
9. Member of the IFIP Technical Committee 1 (Theoretical Computer Science), 2001-2016. (Hungarian representative)

10. Member of the Steering Committee of the Fundamentals of Computation Science conferences, 1998-2016.

11. Member of the EATCS, 1985-2016.

Membership in Learned Bodies, Professional Associations and Committees in Hungary

1. Member of the Scientific and Habilitation Committee, University of Debrecen, Faculty of Informatics, 2010-2016.

2. Member of the Board of Experts, National Fellowship Committee of Hungary, 2008-2016.

3. Member of the Mathematics Committee of the János Bolyai Fellowship Award, Hungarian Academy of Sciences, 2006-2015.

4. Member of the Computer Science Committee of the Hungarian Academy of Science, 2005-2007, 2002-2004, 1994-1996.

5. Member of the Board for Natural Sciences and Mathematics, National Foundation for Scientific Research of Hungary, 2003-2005.

6. Leader of the PhD Program in Informatics of the University of Szeged, 20012004 .

7. Deputy director of the PhD School in Mathematics and Computer Science of the University of Szeged, 2001-2004.

8. Member of the Computer Science Habilitation Committee, University of Szeged, 1997-2016.

9. Member of the Doctoral Committee of the Faculty of Science of Lajos Kossuth University, Debrecen, 1996-1998.

10. Member of the Mathematical Jury of the Hungarian National Foundation for Scientific Research, 1995-1998.

11. Chairman of the Doctoral Committee of the Institute of Informatics of the Faculty of Science of University of Szeged, 1993-2004.

12. Member of the Doctoral Committee of the Faculty of Science of University of Szeged, 1992-2004. 


\section{Invited Lectures at Conferences, Workshops and Summer Schools}

Trends in Tree Automata and Tree Transducers, Seoul, 2016. Mathematical Foundations of Computer Science, Milan, 2015. Automata, Logic, Formal languages and Algebra, Bordeaux, 2015. The Role of Theory in Computer Science, Waterloo, 2015. Semigroups, Languages and Algebras, Akita, 2014. Weighted Automata: Theory and Applications, Leipzig, 2014. Automata, Logic, Formal languages and Algebra, Stellenbosch, 2013. Mathematics and Informatics, Targu Mures, 2013. Weighted Automata: Theory and Applications, Dresden, 2012. Lattices and Relations, Amsterdam, 2012. Algebras, Languages, Algorithms and Computation, Kyoto, 2011. Highlights of AUTOMATHA, Vienna, 2010. Weighted Automata: Theory and Applications, Leipzig, 2010. Dagstuhl seminar on Quantitative Models, 2010. AUTOMATHA, Liege, 2009. Summer School on Algebraic Theory of Automata, Lisbon, 2008. Developments in Language Theory, Kyoto, 2008. Weighted Automata: Theory and Applications, Dresden, 2008. Algebraic Informatics, Thessaloniki, 2005. Mathematical Foundations of Computer Science, Palics, 2005. Novi Sad Algebraic Conference, 2005. International Ph. D. School of Formal Language Theory and Applications, Tarragona, 2004. Joint Mathematics Meeting, ASM Special Session on Fixed Points, Phoenix, 2004. Weighted Automata: Theory and Applications, Dresden, 2004. Categorical Methods in Computer Science, Warsaw, 2003. International School of Formal Language Theory, Tarragona, 2003. Developments in Language Theory, Kyoto, 2002. Weighted Automata and Applications, Dresden, 2002. Int. Conf. Discrete Mathematics and Applications, Blagoevgrad, 2001. Dagstuhl seminar on Applications of Kleene Algebra, 2001. Expressiveness in Concurrency, Aalborg, 2001. Workshop on Max-Plus Algebras, Prague, 2001. Fixed Points in Computer Science, Florence, 2001. Developments in Language Theory, Vienna, 2001. Dagstuhl Seminar on Logic, Algebra, and Formal Verification, 2000. Category Theory, Como, 2000. Words, Languages and Combinatorics, Kyoto, 2000. Algebraic Engineering, Aizu, 1997. Logic in Computer Science, Novi Sad, 1995. Mathematical Foundations of Computer Science, Kosice, 1994. IMYCS, Smolenice, 1988.

\section{Other conference and seminar presentations}

Talks at cca. 80 international conferences and workshops. Seminar and/or colloquium presentations at the following universities and research centers (several talks at some places): University of Aalborg, BRICS, Aarhus, University of Aizu, CWI, Amsterdam, Autonomous University of Barcelona, LaBRI, University of Bordeaux, University of Bremen, University of Brno, University of Edinburgh, University of Florence, University of Hamburg, University of Hanover, University of Kassel, RIMS, Kyoto, Kyoto Sangyo University, Unversity of Leipzig, University of Linz, University of Magdeburg, University of Matsue, University of Metz, Technical University of Munich, City University of New York, LIAFA, University of Paris 6 and 7, University of Pisa, University of Reykjavik, University of Rome, University 
of Saarbrücken, University of Sao Paulo, Stanford University, Sydney Category Seminar, UCLA, Shimane University, University of Stuttgart, Stevens Institute of Technology, University of Tarragona, University of Tsukuba, University of Turku, TU Vienna, University of Waterloo.

\section{Other Professional Activities}

Member of the Program Committee of DCFS 2016, Bucharest, Highlights of Logic, Games and Automata 2015, Prague, CAI 2015, Stuttgart, AutoMathA 2015, Leipzig, ICALP 2015, Kyoto, Highlights of Logic, Games and Automata 2014, Paris, MFCS 2014, Budapest (co-chair), AFL 2014, Szeged (co-chair), CSR 2014, Moscow, DLT 2013, Paris, MFCS 2013, Wien, CAI 2013, Marseilles, FICS 2012, Tallinn, FSTTCS 2011, Mumbai, DLT 2011, Milan, ICALP 2011, Zurich, AFL 2011, Debrecen, DCFS 2011, Giessen, FSTTCS 2010, Chennai, FICS 2010, Brno, FICS 2009, Coimbra, MEMICS 2009, Brno, DLT 2009, Stuttgart, QUANTLOG 2009, Rhodes (chair), STACS 2009, Freiburg, MEMICS 2008, Brno, LATA 2008, Tarragona, AFL 2008, Balatonfüred (co-chair), DLT 2008, Kyoto, FOSSACS 2008, Budapest, FCT 2007, Budapest (co-chair), LATA 2007, Tarragona, MEMICS 2007, Brno, CAI 2007, Thessaloniki, Algebraic Theory of Automata and Logic, 2006, Szeged, Logic, Models and Computer Science, 2006, Camerino, DLT 2006, Santa Barbara, RELMICS /AKA 2006, Manchester, CSL 2006, Szeged (chair), FOSSACS 2006, Vienna, CSL 2005, Oxford, ICALP 2005, Lisboa, AFL 2005, Dobogókő (co-chair), DLT 2005, Palermo, DLT 2004, Auckland, Process Algebra: Open Problems and Future Directions, Bertinoro, 2003, EXPRESS 2003, Marseilles, FCT 2003, Malmö, FICS 2003, Warsaw (co-chair), DLT 2003, Szeged (co-chair), AFL 2002, Debrecen, FICS 2002, Copenhagen (co-chair), FICS 2000, Paris, AFL 1999, Vasszécsény, FICS 1998, Brno (chair), FOSSACS 1998, Lisbon, Universal Machines and Computations 1998, Metz, FCT 1997, Krakow, Logic in Computer Science LIRA 1997, Novi Sad, AFL 1996, Salgótarján, FCT 1995, Dresden, STACS 1995, Munich, FCT 1993, Szeged (chair).

\section{Professional Awards}

1. Master teacher, Ministry of Education of Hungary, 2005.

2. Széchenyi Professor Award, 1997.

3. Winner of the Gyula Farkas Research Award, János Bolyai Mathematical Society, 1980.

4. Winner of the Kató Rényi Research Award, János Bolyai Mathematical Society, 1974. 


\section{Research Grants}

1. 2014-2016: Extensions of the Theory of Automata and Languages, National Foundation of Hungary for Scientific Research, NKFI K 108448, principal investigator.

2. 2014-2016: Algebraic Structures and Fixed Point Operations in Computer Science, National Foundation of Hungary for Scientific Research, NKFI K 110883, principal investigator.

3. 2012-2014: Extensions and Applications of Fixed Point Theory for NonMonotonic Formalisms. TÉT Greek-Hungarian Bilateral Cooperation. TÉT10-1-2011-0548 (Greek partner: Panos Rondogiannis).

4. 2010: Automata, Languages and Fixed Points. Austrian-Hungarian Action Foundation, 77 öu9 (Austrian partner: Werner Kuich).

5. 2008-2012: Automata, Fixed Points, and Logic, National Foundation of Hungary for Scientific Research, OTKA K 75249, principal investigator.

6. 2005-2010: Member of the Executive Board and Steering Committee of the ESF project AUTOMATHA.

7. 2007-2009: Algebraic Theory of Automata, Hungarian Academy of Science and CNRS, principal co-investigator (French partner: Jean-Eric Pin).

8. 2006-2008: Automata and Formal Languages, Hungarian Academy of Science and Japan Society for the Promotion of Science, MTA-JSPS 101, principal co-investigator. (Japanese partner: Masami Ito).

9. 2001-2004: Iteration theories, Principal Investigator, National Foundation of Hungary for Scientific Research, OTKA T35163.

10. 2001-2002: Algebraic Structures in Automata and Language Theory, AustrianHungarian Action Foundation, 47öu1.

11. 2000-2001: Fixed Points in Language Theory, Principal Investigator, AustrianHungarian cooperative research grant, A-4/1999.

12. 1999-2002: Concurrent Processes and Formal Languages, Principal Investigator, National Foundation of Hungary for Scientific Research, OTKA, T30511.

13. 1999-2000: Fixed Points in Computer Science, Principal Investigator, Ministry of Education of Hungary, FKFP 247/1999.

14. 1997: The Shuffle Operation on Languages and Posets, Japan Society for the Promotion of Science, principal co-investigator. (Japanese partner: Masami Ito). 
15. 1997-2000: Compositions of Tree Automata and Varieties of Tree Languages, Ministry of Education of Hungary, FKFP 704.

16. 1997-99, Algebraic Structures in the Theory of Automata and Formal Languages, Principal Investigator, Austrian-Hungarian Action Foundation.

17. 1997-99, Algebraic Aspects of Automata and Formal Languages, Principal Investigator, French-Hungarian Joint Project, BALATON F28/96.

18. 1997-2000: Iteration Theories, Principal Investigator, Hungarian National Foundation for Scientific Research, T22423.

19. 1996-97: Iteration Theories, Principal Investigator, Ministry of Education of Hungary, 7/1996.

20. 1996-97: Computational Models for Trees, Ministry of Education of Hungary, $665 / 96$.

21. 1995-97: Iteration Theories, Principal Investigator, US-Hungarian Joint Fund, J.F.No. 351.

22. 1995-97: Iteration Theories, Principal Investigator, Hungarian National Foundation for Scientific Research, T16344.

23. 1993: Iteration Theories and Concurrency, Commission of the European Community, CIPA 3511CT920168.

24. 1993-1996: Structural Theory of Automata, Principal Investigator, Hungarian National Foundation for Scientific Research, T7383.

25. 1991-1994: Iteration Theories, Principal Investigator, Hungarian National Foundation for Scientific Research, 2037.

26. 1991-1993: Applications of Iteration Theories, Joint grant with Stephen L. Bloom, Hungarian Academy of Sciences and NSF (USA), INT-90 16123.

27. 1986-1990: Structural Theory of Automata, Principal Investigator, Hungarian National Foundation for Scientific Research, 1144.

\section{Doctoral Students}

László Bernátsky, 2000, Szabolcs Iván, 2008, Zoltán L. Németh, 2008, Tamás Hajgató, 2014. 